\section{RAMP \\ et récepteurs \\ couplés \\ aux protéines G}

Carine Cueille, Jean-Michel Garel
> Les RAMP (receptor activity-modifying protein) modifient le caractère fonctionnel des récepteurs couplés aux protéines G (RCPG) des peptides de la famille de la calcitonine. II semble que I'on puisse étendre l'interaction des RAMP à d'autres RCPG de classe II, puisque ces protéines s'associent aux récepteurs de l'hormone parathyroïdienne, du glucagon et du VIP/PACAP (vasoactive intestinal peptide/pituitary adenylate cyclase activating polypeptide) dénommé également R-VPACl (vasoactive-intestinal peptide PACAP receptor 1 ). Une fonction nouvelle des RAMP émerge de ces observations, car le complexe RAMP2/R-VPACl potentialise la voie de signalisation des phospho-inositides. La régulation de l'expression des RAMP à un niveau transcriptionnel ou post-transcriptionnel revêt une certaine importance, puisqu'elle peut influencer la réponse d'une cellule cible à un ligand, en modifiant le caractère fonctionnel d'un RCPG de classe II ou en affectant le niveau d'une voie de signalisation de ces récepteurs. <

Le fonctionnement des récepteurs couplés aux protéines $G(R C P G)$ est connu depuis des décennies, mais un pas important a été franchi récemment, lorsqu'il a été montré que le caractère fonctionnel de certains récepteurs dépendait d'interactions protéiques de nature différente. Le rôle de ces interactions dans la localisation des RCPG et la transduction du signal a fait l'objet d'une revue récente [1]. En 1998, la découverte des RAMP (receptor activity-modifying protein), que I'on peut considérer comme des chaperons moléculaires pour les récepteurs du CGRP (calcitonin gene-related peptide) et de l'adrénomédulline (ADM), a modifié notre conception du fonctionnement des RCPG. L'interaction des RAMP avec les RCPG n'est observée, à ce jour, que dans le cas des récepteurs de classe II, c'est-à-dire

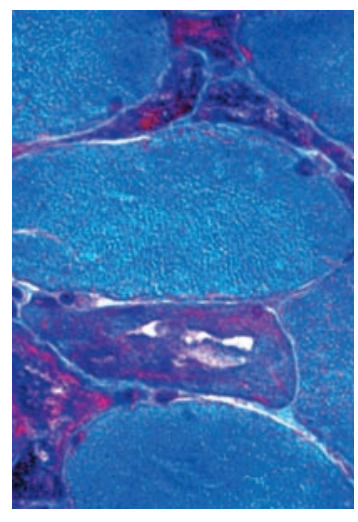

C. Cueille, J.M. Garel: Inserm U.349, Hôpital Lariboisière, 2, rue Ambroise Paré, 75475 Paris Cedex 10, France.

Lean-Michel.Garel@

larib.inserm.fr

des récepteurs de la calcitonine (CTR), de l'hormone parathyroïdienne (RPTH), du glucagon et du VIP/PACAP ou R-VPACl.

\section{Les récepteurs du CGRP et de l'ADM}

Les récepteurs du CGRP (R-CGRP) sont largement présents dans le système nerveux central et périphérique, ainsi que dans le système cardiovasculaire [2]. L'anta-

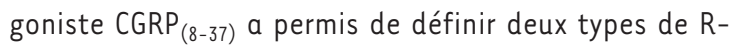
CGRP $[3,4]$ : le R-CGRP ${ }_{1}$ sensible aux propriétés antagonistes du CGRP (8-37), mais peu sensible aux effets agonistes d'un analogue linéaire, le [Cys (ACM)2,7] hCGRP $\alpha$ [4] et le R-CGRP , beaucoup moins sensible au

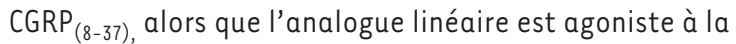
concentration de $10^{-8}$ ou $10^{-7} \mathrm{M}$. Les récepteurs de l'ADM (R-ADM) sont, quant à eux, présents dans de nombreux tissus [5]. En dehors de la moelle épinière, la liaison de I'ADM au niveau du système nerveux est faible, contrairement au CGRP [6]. Les sites de liaison à I'ADM montrent une faible affinité vis-à-vis du CGRP, de l'amyline (AMY) et de la calcitonine, ce qui est en faveur de RADM spécifiques et distincts des R-CGRP [7]. Les récepteurs du CGRP et de I'ADM sont des complexes multiprotéiques composés d'au moins deux éléments [8], le CRLR (calcitonin receptor-like receptor) et les RAMP. La présence d'une troisième molécule, le RCP (receptor coupling protein) est nécessaire à la transduction du signal (Figure 1): cette protéine intracellulaire permet 
l'interaction entre le complexe CRLR/RAMP et la protéine $G$ par un mécanisme qui demeure inconnu [9]. Transfectée dans des ovocytes [10], cette molécule confère des fonctions de R-CGRP; la transduction du signal du R-ADM dépend également du RCP [11]. Le RCP n'est nécessaire ni au routage des récepteurs vers la membrane, ni à l'interaction des RAMP avec le CRLR [11]. Le RCP est présent dans la paroi des vaisseaux sanguins et dans d'autres types cellulaires exprimant le R-CGRP [12]. Une régulation post-transcriptionnelle par la progestérone, augmentant la sensibilité au CGRP, a été décrite dans le myomètre de souris [13]. Le CRLR, identifié en 1993, est un RCPG [14] possédant $55 \%$ d'identité avec le CTR. On sait maintenant qu'il peut à la fois être un récepteur du CGRP et de l'ADM, selon la molécule RAMP qui lui est associée [8] (Figure 1). Associé à la protéine RAMPl, le CRLR a une plus forte affinité pour le CGRP (Tableau IA), tandis que, associé à RAMP2 ou à RAMP3, il forme un récepteur dont l'affinité est plus grande pour l'ADM (Tableau IA). C'est donc l'expression de l'une ou l'autre des trois isoformes de RAMP qui va, dans un tissu particulier, déterminer la capacité de ce tissu à répondre plutôt à l'ADM ou au CGRP. Le récepteur formé par l'hétérodimérisation du CRLR et de RAMPI dans les systèmes recombinants est comparable pharmacologiquement au R-CGRP 1 présent dans les tissus et les lignées cellulaires. Ainsi, la valeur de $\mathrm{pA}_{2}$ (qui définit la puissance de l'antagoniste) pour le $\mathrm{CGRP}_{8-37}$, mesurée après cotransfection du CRLR humain et de RAMPl humain dans les cellules HEK 293, est de 7,6, c'est-à-dire similaire à celle des artères cérébrales humaines isolées $(7,7)$ [15]. Un nouveau R-CGRP, caractérisé à partir du cervelet de rat, n'impliquant pas un CRLR, pourrait correspondre au $\mathrm{R}-\mathrm{CGRP}_{2}$ [16].

\section{Les RAMP}

\section{Caractéristiques générales}

II existe trois isoformes de RAMP: RAMP1, 2 et 3 . Exprimées dans de très nombreux tissus, elles ont moins de $30 \%$ d'identité de séquence, mais présentent des similitudes d'organisation structurale (Figure 2). Ce sont de petites protéines intramembranaires (14 à $17 \mathrm{kDa}$ ) possédant un domaine extracellulaire important (environ 100 résidus), un domaine transmembranaire et un domaine intracellulaire très court (10 résidus). Clonées au départ chez l'homme, les RAMP ont été clonées par la suite chez le rat et la souris [17]. Dans ces trois espèces, pour RAMPl et RAMP3, six cystéines sont conservées dans le domaine extracellulaire, quatre d'entre elles étant présentes dans RAMP2 (Figure 2). RAMPl est caractérisée par l'absence de sites de N-glycosylation. RAMP2 et RAMP3 présentent des sites de N-glycosylation dont le nombre est variable en fonction de l'espèce (Figure 2). Un site consensus de phosphorylation par la protéine kinase $C$ est présent dans le domaine intracellulaire carboxyterminal de RAMPl et de RAMP3, mais pas de RAMP2 (Figure 2).

Les gènes codant pour RAMP1 et RAMP3 ont une structure comparable [17] avec trois exons et un intron (> $17 \mathrm{~kb}$ ) séparant les deux premiers exons; le deuxième intron séparant les exons deux et trois est plus petit (> $5 \mathrm{~kb}$ ). L'organisation du gène codant pour RAMP2 est différente et comporte quatre exons séparés par de courts introns
$(<0,4 \mathrm{~kb})$. Les gènes codant pour RAMP1, RAMP2 et RAMP3 sont portés respectivement par les chromosomes 2, 17 et 7 chez l'homme.

Les RAMP sont exprimés dans la plupart des tissus et des lignées cellulaires. À défaut de la protéine, c'est la présence de l'ARNm qui a été étudiée. Les transcrits d'une forme de RAMP peuvent être plus abondants que ceux des deux autres. Ainsi, pour le cerveau, le pancréas et les gonades, les ARNm de RAMPl et RAMP3 prédominent sur l'expression de RAMP2. En revanche, les ARNm de RAMP2 et de RAMP3 sont plus abondants que ceux de RAMPl au niveau des poumons, de la trachée, du système immunitaire, du rein et du fœtus. Le foie est un organe pour lequel une expression équivalente des trois RAMP a été observée [17]. Les études de liaison par radioligands ont montré une corrélation entre le phénotype du récepteur endogène et l'expression tissulaire d'un RAMP donné en présence de CRLR [5]. En d'autres termes, une corrélation élevée existe entre l'expression de RAMP1 et la liaison au CGRP et entre RAMP2 et la liaison à l'ADM. L'équilibre entre le taux de RAMPI d'un côté et le taux de RAMP2 + RAMP3 de l'autre pourrait orienter l'affinité de liaison du CGRP et de I'ADM, et les RAMP pourraient entrer en compétition pour déterminer la spécificité du ligand [18].

\section{Rôles fonctionnels}

En plus de leur implication dans le déterminisme de la spécificité pharmacologique du CRLR et du CTR, les RAMP contrôlent également la glycosylation et le transport du CRLR vers la membrane. Enfin, les RAMP sont susceptibles d'amplifier une voie de transduction.

\section{Chaperons moléculaires}

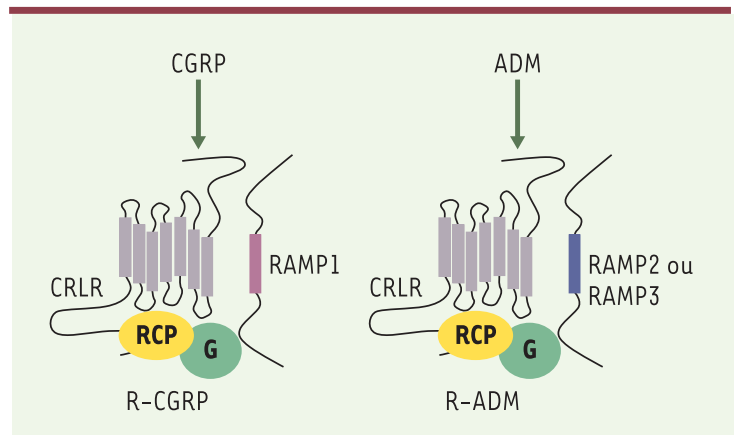

Figure 1. Récepteurs du CGRP (calcitonin gene-related peptide) (R-CGRP) et de l'ADM (adrénomédulline) (R-ADM). Ces récepteurs sont des complexes hétérotrimériques formés par le CRLR (calcitonin-receptor-like receptor), un RAMP (receptor activity-modifying protein) et le RCP (receptor coupling protein). Ces complexes sont associés à une protéine $G$, ellemême couplée à un effecteur. 
L'adressage vers la membrane cellulaire a été étudié dans le cas du CRLR et du CTR. Dans le cas du CRLR, il a été montré par microscopie confocale que la co-expression avec des RAMP était nécessaire pour le transport du récepteur à la membrane plasmique (Figure 3). La réciproque est vraie: les RAMP ont besoin du CRLR pour leur translocation à la surface cellulaire [19]. Si l'expression individuelle de RAMP2 et de RAMP3 à la surface cellulaire nécessite une N-glycosylation, RAMPl n'est pas glycosylée, ce qui nécessiterait l'intervention du CRLR pour son expression à la surface cellulaire (Figure 3).

Le CTR, à l'opposé du CRLR, n'a pas besoin des RAMP pour sa localisation à la membrane cellulaire (Figure 3 ). En revanche, le CTR comme le CRLR entraîne une translocation à la surface cellulaire des RAMP. La cotransfection dans les cellules COS-7 de CTR augmente l'expression à la surface cellulaire de RAMPI étiquetée par myc [20]. Myc-RAMPl exprimé seul n'est pas détecté à la surface cellulaire, il est retenu au niveau intracellulaire. RAMPl modifie la glycosylation finale du CRLR et permet l'apparition d'un phénotype de récepteur du CGRP caractérisé par la masse moléculaire la plus élevée. Des expériences de co-immunoprécipitation de la protéine étiquetée ont montré que RAMPl est directement complexé aux formes immatures et mature du CRLR avec présence à la surface cellulaire de la forme mature du CRLR complexée à RAMPl.

Les études d'immunofluorescence en microscopie confocale ont montré que les RAMP interagissent avec quatre autres récepteurs

A. Interactions CRLR/RAMP

$\begin{array}{lcccccccc} & & \alpha C G R P & \beta C G R P & \text { CGRP }_{\mathbf{8 - 3 7}} & \text { ADM } & \text { ADM }_{22-52} & \text { AMY } & \text { Type cellulaire } \\ \text { CRLR } & \text { RAMP1 } & \mathbf{1 0} & \mathbf{1 1} & \mathbf{9 , 5} & \mathbf{8 , 1} & \mathbf{6 , 4} & \text { NS } & \text { Swiss3T3 } \\ & & \mathbf{9 , 6} & \mathbf{9 , 8} & \mathbf{9 , 1} & \mathbf{6 , 8} & & & \text { HEK293 } \\ \text { CRLR } & \text { RAMP2 } & 5,9 & \mathbf{6 , 5} & 7,1 & 9,2 & 7,8 & \text { NS } & \text { Swiss3T3 } \\ \text { CRLR } & \text { RAMP3 } & \mathbf{6 , 5} & \mathbf{7 , 1} & \mathbf{7 , 3} & 8,3 & 7,1 & & \text { HEK293 }\end{array}$

B. Interactions CTR/RAMP en présence d'amyline

\begin{tabular}{|c|c|c|c|c|c|c|}
\hline & & hCT & sCT & rAMY & h $\alpha$ CGRP & \\
\hline CTRa & & 7,81 & 9,03 & 6,27 & $>6$ & COS -7 \\
\hline CTRa & RAMPI & 7,53 & 9,51 & 8,1 & 7,67 & $\cos -7$ \\
\hline CTRa & RAMP2 & 8,08 & 9,89 & 7,82 & 5,86 & $\cos -7$ \\
\hline CTRa & RAMP3 & 7,71 & 9,68 & 8,2 & 6,82 & $\cos -7$ \\
\hline CTRb & & 9,45 & 10,56 & 6,58 & 6,77 & $\cos -7$ \\
\hline CTRb & RAMPI & 6,94 & 10,98 & 8,43 & 9,93 & $\cos -7$ \\
\hline CTRb & RAMP2 & 7,95 & 9,33 & 8,23 & 7,72 & $\cos -7$ \\
\hline CTRb & RAMP3 & 6,87 & 9,16 & 8,19 & 7,1 & COS -7 \\
\hline
\end{tabular}

Tableau I. Profils pharmacologiques des interactions entre le CRLR (calcitonin receptor-like receptor) humain ou le récepteur de la calcitonine (CTR) humain et les RAMP (receptor activity-modifying protein) humaines. A. Profil pharmacologique des interactions CRLR/RAMP. Les valeurs représentent la $\mathrm{pIC}_{50}$ (logarithme négatif de la concentration de ligand permettant un déplacement de $50 \%$ du ligand marqué) mesurée pour différents ligands contre le CGRP ${ }^{125}$ I (en gras) ou l'adrénomédulline ( $\left.A D M\right)^{125}$ I (en caractères normaux). Les résultats pour les deux isoformes $\alpha$ et $\beta$ du CGRP (calcitonin gene-related peptide) sont présentés. $B$. Profil pharmacologique des interactions CTR/RAMP en présence d'amyline (AMY) ${ }^{125}$ I. ADM $22-52$ : antagoniste de l'ADM. $r$ : rat; s: saumon; $h$ : homme. Les résultats pour les deux isoformes a et b du CTR humain sont présentés (modifié d'après [22]). appartenant à la classe II des RCPG. II s'agit des récepteurs du glucagon et de l'hormone parathyroïdienne (PTHRl) qui interagissent avec RAMP2. Le récepteur 2 de la PTH interagit, quant à lui, avec RAMP3, tandis que le récepteur du VIP/PACAP ( $R$ VPACl) interagit avec les trois RAMP [21]. Ces interactions augmentent l'expression de ces RAMP à la surface cellulaire.

\section{Spécificité de liaison du ligand} plexes ne sont pas établies, les deux types de récepteurs possédant les mêmes caractéristiques [22]. La similitude entre le CRLR et le CTR a suscité des études sur les interactions entre et CTR, montrant que la co-expression de RAMPl et de d'un site de liaison du ligand ou à une régulation allostérique de la conformation du CRLR [25]. En effet, la cotransfection dans les cellules HEK 293 du CRLR humain et de mutants de RAMPI humain privés des résidus 91 à 94,96 à 100 , ou 101 à 103 empêche la liaison du CGRP ${ }^{125}$ l et abolit la production d'AMPc induite par le CGRP [25].

Plusieurs hypothèses ont rapidement vu le jour concernant le mécanisme d'action des RAMP: est-ce l'état de glycosylation du CRLR qui détermine la spécificité du récepteur, la présence de l'une ou l'autre isoforme de RAMP ou un changement de conformation du CRLR induit par la molécule chaperonne exprimée [26]? Des transfections, 
dans les cellules S2 de drosophile, d'hétérodimères RAMP1/CRLR ou RAMP2/CRLR entraînent la mise en place des récepteurs aux propriétés pharmacologiques attendues, mais non glycosylés [27]. Un autre travail montre que l'interaction RAMP/CRLR est plus importante pour la spécificité du type de récepteur que l'état de glycosylation [28] et que RAMP1 et RAMP2 glycosylent le CRLR de la même façon. II semble donc que les différences pharmacologiques entre RAMPl/CRLR et RAMP2/CRLR soient dues à la présence d'un type de RAMP à la surface membranaire plutôt qu'à l'état de glycosylation du CRLR, même si la glycosylation est importante pour la maturation et l'expression du récepteur à la surface membranaire [29]. Dans le cas des R-ADM, certains acides aminés des RAMP pourraient participer à la formation de la poche de liaison de I'ADM [30]: sept acides aminés (aa) situés entre trois résidus conservés dans le domaine aminoterminal extracellulaire, les aa 86-92 du hRAMP2 et 59-65 du hRAMP3, sont essentiels à la liaison du ligand et à la fonctionnalité du récepteur. Des récepteurs de I'AMY sont obtenus dans des systèmes cellulaires par cotransfection de CTR avec les trois RAMP (Tableau IB). La situation est compliquée par le fait qu'il existe deux isoformes de CTR chez l'homme (CTRa et CTRb), l'isoforme $\beta$ ayant une faculté plus grande à former avec RAMP2 des récepteurs à l'AMY que le CTRa [31]. Le complexe RAMPI/CTR présente des affinités élevées pour différents ligands: I'IC ${ }_{50}^{1}$ est de $0,3 \mathrm{nM}$ pour la CT de saumon, de 7,8 nM pour l'AMY et de 20,9 nM pour le CGRP. En revanche, l'affinité est beaucoup plus faible pour la CT humaine avec une $I_{50}$ de 447 nM. Les propriétés pharmacologiques du récepteur de I'AMY résultant de l'interaction RAMP3/CTR sont à peu près identiques à celles de RAMPI/CTR, sauf pour le CGRP dont l'affinité est plus faible [20]. La signification physiologique de ces différents types de récepteurs n'étant pas connue, il est possible de classer les récepteurs de I'AMY en fonction de leur interaction avec un RAMP donné (AMY1, AMY2, AMY3) et également en fonction de la nature de l'isoforme de CTR. Ainsi, on peut avoir un AMYla et un AMylb.

Il a été montré que la cotransfection dans les cellules COS-7 des différents RAMP ne change pas la $\mathrm{pIC}_{50}{ }^{2}$ du VIP ${ }^{125}$ | déplacé par différents ligands [21] ce qui montre que le phénotype du récepteur VPACl n'est pas altéré par la présence des RAMP.

\section{Amplification d'une voie de transduction} La co-expression dans les cellules COS-7 du récepteur VPACl et de RAMP2 augmente l'hydrolyse des phosphoinositides en réponse au VIP [21]. En revanche,

${ }^{1} \mathrm{C}_{50}$ : concentration inhibant de $50 \%$ l'amplitude de l'effet d'un agoniste administré à une dose donnée non maximale.

${ }^{2} \mathrm{PIC}_{50}$ : logarithme négatif de la concentration de ligand permettant un déplacement de $50 \%$ du ligand radiomarqué. aucun effet significatif n'est visible sur la production d'AMPc induite par le VIP.

\section{Régulation de l'expression des RAMP}

Chez le rat, l'insuffisance cardiaque induite par ligature de l'artère coronaire gauche accroît l'expression des ARNm de RAMP2 et du CRLR [32, 33], ce qui suggère une augmentation des récepteurs de I'ADM. En revanche, l'insuffisance cardiaque induite par sténose aortique chez le rat augmente l'expression de RAMPl et de RAMP3 (ARNm et protéine) [34]. Dans le modèle de fibrose rénale du rat obtenu par obstruction unilatérale de l'uretère, le taux des ARNm de RAMPl est très augmenté, celui de RAMP2 faiblement accru, et celui de RAMP3 inchangé [35]. L'expression des ARNm des RAMP est modifiée de façon spécifique des tissus chez la souris atteinte de septicémie [36]. Si RAMP3 est augmenté dans le poumon, en revanche RAMPl diminue légèrement et RAMP2 devient indétectable. Pour le cœur et le thymus, RAMP3 est inchangé, mais RAMPl et RAMP2 sont légèrement diminués [36]. Chez le rat placé en hypoxie, l'expression de RAMPl et de RAMP3 est augmentée au niveau du poumon [37]. La dexaméthasone stimule l'expression in vitro des ARNm de RAMPl et du CRLR dans les cellules musculaires lisses vasculaires humaines [38]. Chez la femme atteinte d'hypertension gravidique, l'expression de l'ARNm codant pour RAMP2 et pour le CRLR est diminuée à la fois dans le muscle utérin mais aussi dans l'artère ombilicale [39]. Un aspect nouveau et intéressant du contrôle de l'expression de RAMP3 est fourni par les expériences sur les cellules mésangiales de rat traitées au PDGF (platelet-derived growth factor) [40]. Ce facteur de croissance augmente le taux des
MASLRVERAGGPRLPRTRVGRPAAVRL

MARALCRLPRRGLWLLLAHHLFMTTACPEANYGALLRELCLT PFQVDMEAVGETLWCDWGRT L L L L GAVLNPHEALA PPLPT T GTPGSEGGTVKNYETAVPFCWNHYKD PMDP|EKDWCDWAMI METGALRRPQLLPL L L L LCGGCPRAGGCNETGML \& R LPLCGKAFADMMG KVDVWKWCNLS $\varepsilon F$

IRSYRELADCTWHMAEKLGCFWPNAEVDRFFLAVHGRYFRSCPISGRAVRDPPGSILYPFIV SRPYSTLRDCLEHFAELFDLGFPN LAERIIFETH PI H FANCSLV PPT FS DPPEDVLLAMII IVYYEESFTNCTEMEANVVGCYWPNPLA QGFITGIHR PFSNCTVDRVHLEDPPDEVLIPLIV
VPITVTLLVTALVVWPSKRTEGIV APICLIPFLITLVVWRSKDS EAPA I PVVLPVAMAGLV V WRSKRTDTLL
RAMP 1
RAMP 2
RAMP3

Figure 2. Séquences en acides aminés des RAMP (receptor activity-modifying protein) humains. L'identité entre les trois RAMP, qui est très faible (moins de $30 \%$ ), n'a pas été représentée. Les séquences ont été alignées à partir du segment transmembranaire (en gras). Les sites de glycosylation $(N)$ sont indiqués en italique. Les cystéines $(C)$ conservées entre les trois espèces (homme, rat, souris) sont indiquées en gras. Les sites de phosphorylation sont indiqués par une astérisque. 
ARNm et la teneur en protéine sur la membrane plasmique, mais c'est la demi-vie de l'ARNm qui est accrue par un mécanisme impliquant les MAP kinases.

\section{Perspectives}

L'identification en 2003 d'un nouveau peptide, l'intermédine, membre de la famille de la CT [41], a montré qu'il agissait par l'intermédiaire d'un récepteur constitué du CRLR et d'un RAMP, sans spécificité particulière pour l'un des trois RAMP. Ce nouveau venu vient compliquer davantage le jeu des ligands interagissant avec le CRLR associé à un RAMP. Nos travaux récents sur la cellule musculaire lisse vasculaire humaine en hypoxie laissent penser que la protéine CRLR fait l'objet d'une régulation très rapide et que la régulation post-transcriptionnelle revêt une importance plus grande que la régulation transcriptionnelle par HIF-l $\alpha$ (hypoxia inducible factor $1 \alpha$ ). $\diamond$

\section{SUMMARY}

RAMPs and G protein coupled receptors

RAMPs (receptor activity-modifying proteins) were discovered in 1998 as accessory proteins needed to the functionnal activity of CGRP (calcitonin gene-related peptide) receptors. Three RAMPs generated by three different genes are known in human, rat and mice. The coding sequences of such genes are described, but as yet, regulation sequences are unknown. RAMPs interact with GPCR (G protein-coupled receptors) of class II. In the case of the calcitonin/CGRP peptide family, RAMPs determine the functionnal specificity of the receptor, glycosylate and translocate the receptor to the cell surface. CGRP receptors are observed in presence of the RAMPl/calcitonin receptor-like receptor (CRLR), but the association of RAMP2 or RAMP3 with CRLR generates an adrenomedullin receptor. The calcitonin receptor (CTR) is translocated alone to the cell surface, but interactions of RAMPs with CTR forms amylin receptors. If RAMPs can interact with glucagon, parathyroid

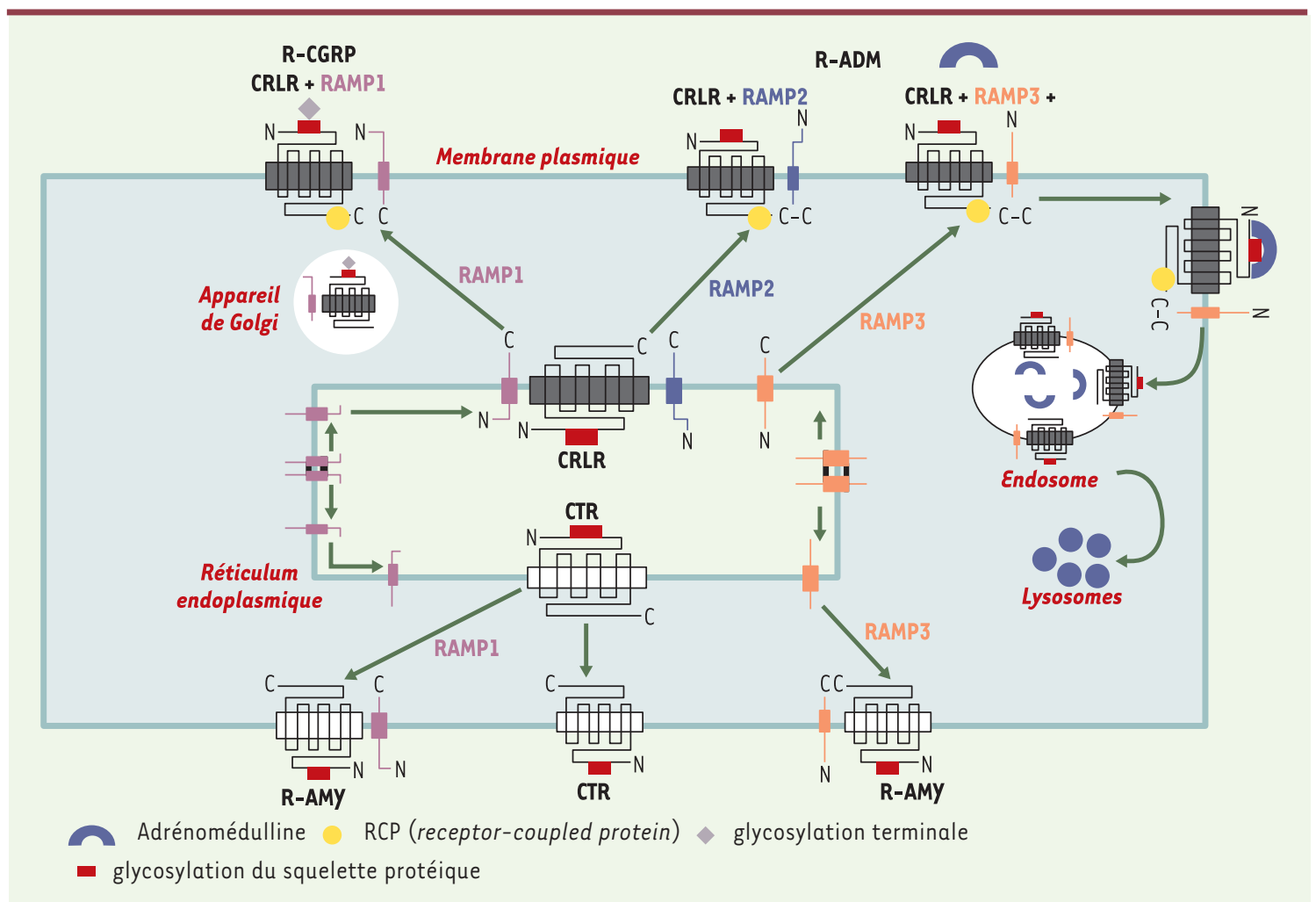

Figure 3. Rôle des RAMP (receptor activity-modifying protein) sur le CRLR (calcitonin receptor-like receptor) et le récepteur de la calcitonine (CTR). RAMP1 (mais pas RAMP2 ni RAMP3) modifie la glycosylation aminoterminale de CRLR. Le complexe cellulaire de surface RAMP1-CRLR est un récepteur du CGRP (calcitonin gene-related peptide) de type 1. Les complexes de surface RAMP2CRLR et RAMP3-CRLR sont des récepteurs de l'adrénomédulline (R-ADM). Contrairement au CRLR, le CTR est acheminé à la membrane en l'absence de RAMP. Les complexes RAMP1-CTR et RAMP3-CTR forment des récepteurs de l'amyline distincts (R-AMY) (modifié d'après [17]). 
hormone and VIP/PACAP (vasoactive intestinal peptide/pituitary adenylate cyclase activating polypeptide (VPACRl)) receptors, the functionnal specificity of these receptors remains unaltered. However, the complex VPACR1/RAMP2 enhances specifically the phosphoinoside signaling pathway. $\diamond$

\section{RÉFÉRENCES}

1. Brady AE, Limbird LE. G protein-coupled receptor interacting proteins: Emerging roles in localization and signal transduction. Cell Signal 2002 ; 14: 297-309.

2. Wimalawansa SJ. Calcitonin gene-related peptide and its receptors: Molecular genetics, physiology, pathophysiology, and therapeutic potentials. Endocrinol Rev 1996; 17: 533-85.

3. Dennis T, Fournier A, Cadieux A, et al. hCGRP8-37, a calcitonin generelated peptide antagonist revealing calcitonin gene-related peptide receptor heterogeneity in brain and periphery. J Pharmacol Exp Ther $1990 ; 254: 123-8$.

4. Quirion R, Van Rossum D, Dumont Y, et al. Characterization of CGRPI and CGRP2 receptor subtypes. Ann NY Acad Sci 1992; 657: 88-105.

5. Chakravarty P, Suthar TP, Coppock HA, et al. CGRP and adrenomedullin binding correlates with transcript levels for calcitonin receptor-like receptor (CRLR) and receptor activity-modifyng proteins (RAMPs) in rat tissues. BrJ Pharmacol 2000; 130: 189-95.

6. Wimalawansa SJ. Amylin, calcitonin gene-related peptide, calcitonin, and adrenomedullin: A peptide superfamily. Crit Rev Neurobiol 1997; 11: 167-239.

7. Nandha KA, Taylor GM, Smith DM, et al. Specific adrenomedullin binding sites and hypotension in the rat systemic vascular bed. Regul Pept 1996; 62: 145-51.

8. McLatchie L, Fraser NJ, Main MJ, et al. RAMPs regulate the transport and ligand specificity of the calcitonin receptor like receptor. Nature 1998; 393: 333-9.

9. Evans BN, Rosenblatt MI, Mnayer L0, et al. CGRP-RCP, a novel protein required for signal transduction at calcitonin gene-related peptide and adrenomedullin receptors. J Biol Chem 2000; 275: 31438-43.

10. Luebke AE, DahI GP, Roos BA, Dickerson IM. Identification of a protein that confers CGRP responsiveness to oocytes using CFTR assay. Proc Natl Acad Sci USA 1996; 93: 3455-60.

11. Prado MA, Evans-Bain B, Oliver KR, Dickerson IM. The role of the CGRPreceptor component protein $(R C P)$ in adrenomedullin receptor signal transduction. Peptides 2001; 22: 1773-81.

12. Prado MA, Evans-Bain B, Dickerson IM. Receptor component protein (RCP): A member of a multi-protein complex required for $\mathrm{G}$-proteincoupled signal transduction. Biochem Soc Trans 2002; 30: 460-4.

13. Naghashpour M, Dahl G. Sensitivity of myometrium to CGRP varies during mouse estrous cycle and in response to progesterone. Am J Physiol Cell Physiol 2000; 278: C561-9.

14. Njuki F, Nicholl CG, Howard A, et al. A new calcitonin-receptor-like sequence in rat pulmonary blood vessels. Clin Sci 1993; 85 : 385-8.

15. Edvinsson L, Sams A, Jansen-Olesen I, et al. Characterisation of the effects of a non-peptide CGRP receptor antagonist in SK-N-MC cells and isolated human cerebral arteries. Eur J Pharmacol 2001; 415: 39-44.

16. Chauhan M, Thota CS, Kondapaka S, et al. Evidence for the existence of a new receptor for CGRP, which is not CRLR. Peptides 2003; 24 : 65-71.

17. Sexton PM, Albiston A, Morfis M, Tilakaratne N. Receptor activity modifying proteins. Cell Signal 2001; 13: 73-83.

18. Buhlmann N, Aldeoca A, Leuthauser K, et al. Glycosylation of the calcitonin receptor like receptor at Asn (60) or Asn(112) is important for cell surface expression. FEBS Lett $2000 ; 486: 320-4$.

19. Flahaut M, Rossier BC, Firsov D. Respective roles of calcitonin receptorlike receptor (CRLR) and receptor activity-modifying proteins (RAMP) in cell surface expression of CRLR/RAMP heterodimeric receptors. J Biol Chem 2002; 277: 14731-7.

20. Christopoulos G, Perry KJ, Morfis M, et al. Multiple amylin receptors arise from receptor activity-modifying protein interaction with the calcitonin receptor gene product. Mol Pharmacol 1999; 56: 235-42.

21. Christopoulos A, Christopoulos G, Morfis M, et al. Novel receptor partners and function of receptor activity-modifying proteins. J Biol Chem 2003; 278: 3293-7.
22. Poyner DR, Sexton PM, Marshall I, et al. International union of pharmacology. XXXII. The mammalian calcitonin gene-related peptides, adrenomedullin, amylin, and calcitonin receptors. Pharmacol Rev 2002; 54: 233-46.

23. Armour SL, Foord S, Kenakin T, Chen WJ. Pharmacological characterization of receptor-activity-modifying proteins (RAMPs) and the human calcitonin receptor. J Pharmacol Toxicol Meth 1999; 42: 217-24.

24. Muff R, Buhlmann N, Fisher JA, Born W. An amylin receptor is revealed following co-transfection of a calcitonin receptor with receptor activity modifying protein. Endocrinology 1999; 140: 2924-27.

25. Kuwasako K, Kitamura K, Nagoshi Y, Eto T. Identification of the human receptor activity-modifying protein 1 domains responsible for agonist binding specificity. J Biol Chem 2003; 278: 22623-30.

26. Foord SM, Marshall FH. RAMPs: Accessory proteins for seven transmembrane domain receptors. Trends Pharmacol Sci 1999; $20: 184-7$.

27. Aldecoa A, Gujer R, Fisher JA, Born W. Mammalian calcitonin receptor-like receptor/receptor activity modifying protein complexes define calcitonin gene-related peptide and adrenomedullin receptors in Drosophila Schneider 2 cells. FEBS lett 2000; 471: 156-60.

28. Hilairet S, Foord SM, Marshall FH, Bouvier M. Protein-protein interaction and not glycosylation determines the binding selectivity of heterodimers between the calcitonin receptor-like receptor and the receptor activitymodifying proteins. J Biol Chem 2001; 276: 29575-81.

29. Gujer R, Aldecoa A, Buhlmann N, et al. Mutations of the asparagine 117 residue of a receptor activity-modifying protein 1 dependent human calcitonin gene-related peptide receptor result in selective loss of function. Biochemistry 2001; 40: 5392-8.

30. Kuwasako K, Kitamura K, Ito K, et al. The seven amino acids of human RAMP2 (86) and RAMP3 (59) are critical for agonist binding to human adrenomedullin receptors. J Biol Chem 2001; 276: 49459-65.

31. Tilakaratne N, Christopoulos G, Zumpe ET, et al. Amylin receptor phenotypes derived from human calcitonin receptor/RAMP coexpression exhibit pharmacological differences dependent on receptor isoform and host cell environment. J Pharmacol Exp Ther 2000; 294: 61-72.

32. Totsune KO, Takahashi K, Mackenzie HS, et al. Increased gene expression of adrenomedullin and adrenomedullin-receptor complexes, receptoractivity modifying protein (RAMP) 2 and calcitonin-receptor-like receptor (CRLR) in the heart of rats with congestive heart failure. Clin Sci 2000; 99: 541-6.

33. Oie $\varepsilon$, Vinge $L \varepsilon$, Yndestad $A$, et al. Induction of a myocardial adrenomedullin signalling system during ischemic heart failure in rats. Circulation 2000; 101: 415-22.

34. Cueille C, Pidoux E, De Vernejoul MC, Garel JM. Increased myocardial expression of RAMP1 and RAMP3 in rats with chronic heart failure. Biochem Biophys Res Commun 2002; 294: 340-6.

35. Nagae T, Mukoyama M, Sugawara A, et al. Rat receptor-activitymodifying proteins (RAMPs) for adrenomedullin/CGRP receptor: Cloning and upregulation in obstructive nephropathy. Biochem Biophys Res Commun 2000; 270: 89-93

36. Ono Y, Okano I, Kojima M, et al. Decreased gene expression of adrenomedullin receptor in mouse lungs during sepsis. Biochem Biophys Res Commun 2000; 271: 197-202.

37. Ping X, Svaren J, Keith IM. mRNA expression of novel CGRPI receptors and their activity-modifying proteins in hypoxic rat lung. Am J Physiol Lung Cell Mol Physiol 2001; 280: L547-54.

38. Frayon S, Cueille C, Gnidéhou S, et al. Dexamethasone increases RAMPI and CRLR mRNA expressions in human vascular smooth muscle cells. Biochem Biophys Res Commun 2000; 270: 1063-7.

39. Makino Y, Shibata K, Makino I, et al. Alteration of the adrenomedullin receptor component gene expression associated with the blood pressure in pregnancy-induced hypertension. J Clin Endocrinol Metab 2001; 86: 5079-82

40. Nowak W, Parameswaran N, Hall CS, et al. Novel regulation of adrenomedullin receptor by PDGF: Role of receptor activity modifying. Am J Physiol Cell Physiol 2002; 282: C1322-31.

41. Roh J, Chang CL, Bhalla A, et al. Intermedin is a calcitonin/calcitonin gene-related peptide family peptide acting through the calcitonin receptor-like receptor/receptor activity-modifying protein receptor complexes. J Biol Chem 2004; 279: 7264-74.

\section{TIRÉS À PART}

J.M. Garel 